\title{
Treatment of Class II Division 2 Pattern Malocclusion Using Protraction Utility Arch in a Prepubertal Patient: A Clinical Case Report
}

\author{
Sridhar Kannan ${ }^{1}$, Sweta Saravanan ${ }^{2}$, Nitin Arora ${ }^{3}$, Ashish Kumar Singh ${ }^{4}$, Abhita Malhotra ${ }^{5}$, Madhuri Bhatia ${ }^{6}$
}

\begin{abstract}
Class II malocclusions are one of the most commonly encountered problems in orthodontics. A class II division 2 type of malocclusions is one in which there is distocclusion of the molars along with retroclined central incisors. These occur but quite rarely in the practice and not many varieties of treatment modalities have been published in the recent literature. The use of protraction and retraction utility arch has been advocated in the following case along with fixed orthodontic treatment in a prepubertal male child to obtain stable results.

Keywords: Class II division 2, Protraction, Retraction, Utility arch.

International Journal of Clinical Pediatric Dentistry (2020): 10.5005/jp-journals-10005-1753
\end{abstract}

\section{INTRODUCTION}

Class II type malocclusion is one of the most commonly observed problems in the practice of orthodontics. It is generally explained as the distally placed relation of the mandibular arch in relation to the maxillary arch along with an amalgamation of distinctive components of the dentition and skeleton. ${ }^{1}$ This affects not only esthetics of the face but also the functional status of the patient. The relationship between esthetics of the face and occlusal relationship sagittally has been constantly researched since Angle's studies wherein the sagittal deviations in occlusion were observed. These produced various in the disharmonies of facial contours of the patient. In 1899, Angle classified sagittal occlusal relationships into three broad categories/classes based mostly on the anteroposterior relationship of the maxillary and mandibular first permanent molars. ${ }^{2}$ A class II distocclusion, which he further divided into two: ${ }^{1}$ division with the protrusion of upper incisors $a^{2} d^{2}$ division with the retrusion of upper incisors. Many years later, European orthodontists pointed out the pattern of malocclusion which corresponds to class II, division $2 .^{3}$

\section{History and Etiology}

A prepubertal male patient named Bhavik, aged 11 years, complained of irregularly placed upper front teeth. No relevant family history or dental history was reported. He was internally motivated with a positive attitude toward the orthodontic treatment and cited esthetics as the main reason for taking orthodontic treatment. Physical examination revealed height of $150 \mathrm{~cm}$ and weight $38 \mathrm{~kg}$ with amesomorphic body type.

\section{Clinical Examination}

Extraoral facial examination revealed no asymmetry, and lower third was found to be slightly shorter in the face (Fig. 1). The facial profile was convex with a posterior divergence, straight nose with the nasolabial angle obtuse. The upper and lower lips were normally positioned in relation to the Steiner $\mathrm{S}$ line $(0 \mathrm{~mm})$. The smiling photographs showed an asymmetrical smile with $100 \%$ of the incisal show. The smile arc was nonconsonant and no lateral negative space was present.
${ }^{1-6}$ Department of Orthodontics and Dentofacial Orthopedics, Manav
Rachna Dental College, Faridabad, Haryana, India
Corresponding Author: Ashish Kumar Singh, Department of
Orthodontics and Dentofacial Orthopedics, Manav Rachna Dental
College, Faridabad, Haryana, India, Phone: +918377878380 , e-mail:
drashish.singh@gmail.com
How to cite this article: Kannan S, Saravanan S, Arora N, et al.
Treatment of Class II Division 2 Pattern malocclusion Using Protraction
Utility Arch in a Prepubertal Patient: A Clinical Case Report. Int J Clin
Pediatr Dent 2020;13(4):416-420.
Source of support: Nil
Conflict of interest: None

Intraoral examination showed poor oral hygiene status, Angle's Class I molar bilaterally, class I canine relationship bilaterally, and a class II incisor relationship (Fig. 1). The upper central incisors and lower incisors were retroclined. An overjet of $2 \mathrm{~mm}$ and an overbite of $6 \mathrm{~mm}$ were observed.

\section{Diagnosis}

A 11-year-old prepubertal male patient named Bhavik, with the principal complaint of irregular placement of maxillary anterior teeth, has been diagnosed skeletally as a class I jaw base with retrognathic maxilla and retrognathic mandible, average growth pattern, having class I molar relation on both sides, class I canine relation on both sides, incisor relation-class II division 2, Angle's class I malocclusion with retroclined upper centrals, proclined upper laterals and proclined lower anterior teeth with an overjet of $2 \mathrm{~mm}$ and an overbite of $6 \mathrm{~mm}$ soft tissue with convex profile, obtuse nasolabial angle, normal upper and lower lips, and a lip strain of $2 \mathrm{~mm}$ tongue thrust present.

Bolton analysis showed an overall mandibular discrepancy of about $-0.09 \mathrm{~mm}$ and an anterior mandibular discrepancy of $1.79 \mathrm{~mm}$. Periapical radiographs showed normal bonetrabecula with no pathology. Cephalometric values revealed an ideal relationship between the maxilla and mandible:

() The Author(s). 2020 Open Access This article is distributed under the terms of the Creative Commons Attribution 4.0 International License (https://creativecommons. org/licenses/by-nc/4.0/), which permits unrestricted use, distribution, and non-commercial reproduction in any medium, provided you give appropriate credit to the original author(s) and the source, provide a link to the Creative Commons license, and indicate if changes were made. The Creative Commons Public Domain Dedication waiver (http://creativecommons.org/publicdomain/zero/1.0/) applies to the data made available in this article, unless otherwise stated. 


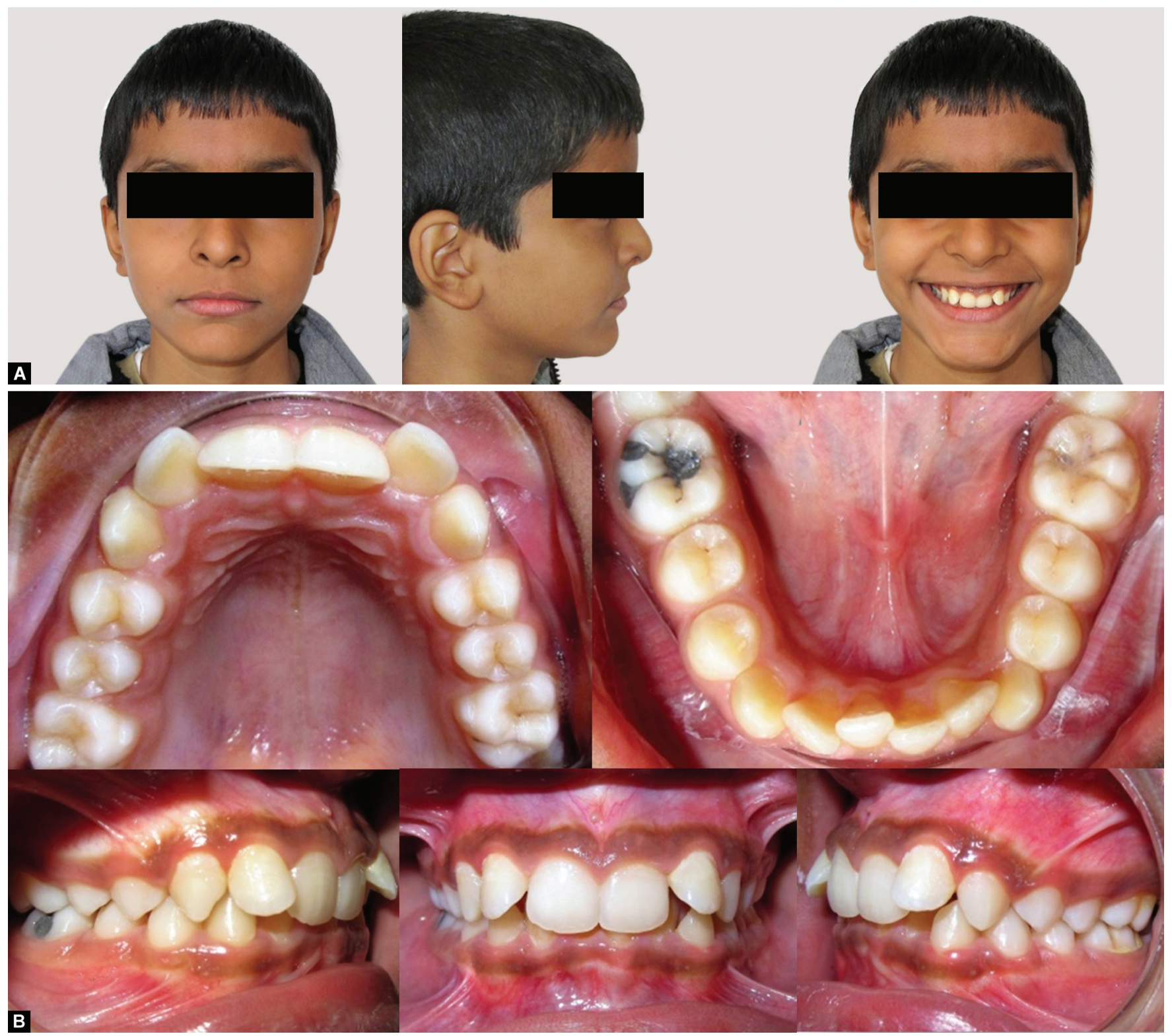

Figs $1 \mathrm{~A}$ and B: Pretreatment photographs: (A) Extraoral; (B) Intraoral

$\mathrm{ANB}=2^{\circ}\left(\mathrm{SNA}=75^{\circ}\right.$ and $\left.\mathrm{SNB}=73^{\circ}\right)$ with a vertical growth pattern-GoGn-SN $=39^{\circ}$ (Fig. 2 and Table 1).

\section{Treatment Objectives}

The objectives of the treatment were as follows: maintain molar, incisor and canine relation, leveling and alignment the arches, correction of overjet and overbite, and to improve the facial profile of the patient by maintaining the balance of the upper lip.

\section{Treatment Plan}

The treatment was commenced with use of a utility arch for the maxillary central incisor $(11,21)$ protraction, and retraction. A removable TPA appliance was given in the maxillary arch during this phase. This was followed by the use of MBT fixed appliance with 0.22 slot for alignment and leveling using round 0.012 -in NiTi wires.
Bands were cemented to the upper and lower arches. 0.014-in to 0.020 -in wires were used to align and level teeth. During finishing, $0.019 \times 0.025$-in archwires were used. Fixed retainers were used for both the maxilla and mandible (Fig. 3).

\section{Treatment Progress}

The patient's chief complaint was irregularly placed upper front teeth. The patient and parent were explained about the need for the protraction and retraction appliance before commencing fixed orthodontic treatment. After placement of the utility arch in the maxillary central incisors, banding was done in the first molars. Upper bonding was done using the MBT brackets and $0.012 \mathrm{NiTi}$ wire was placed. The bite of the patient was raised using composite to aid in bonding the teeth of the lower arch. After bonding, the lower teeth $0.012 \mathrm{NiTi}$ wire was placed. As the 


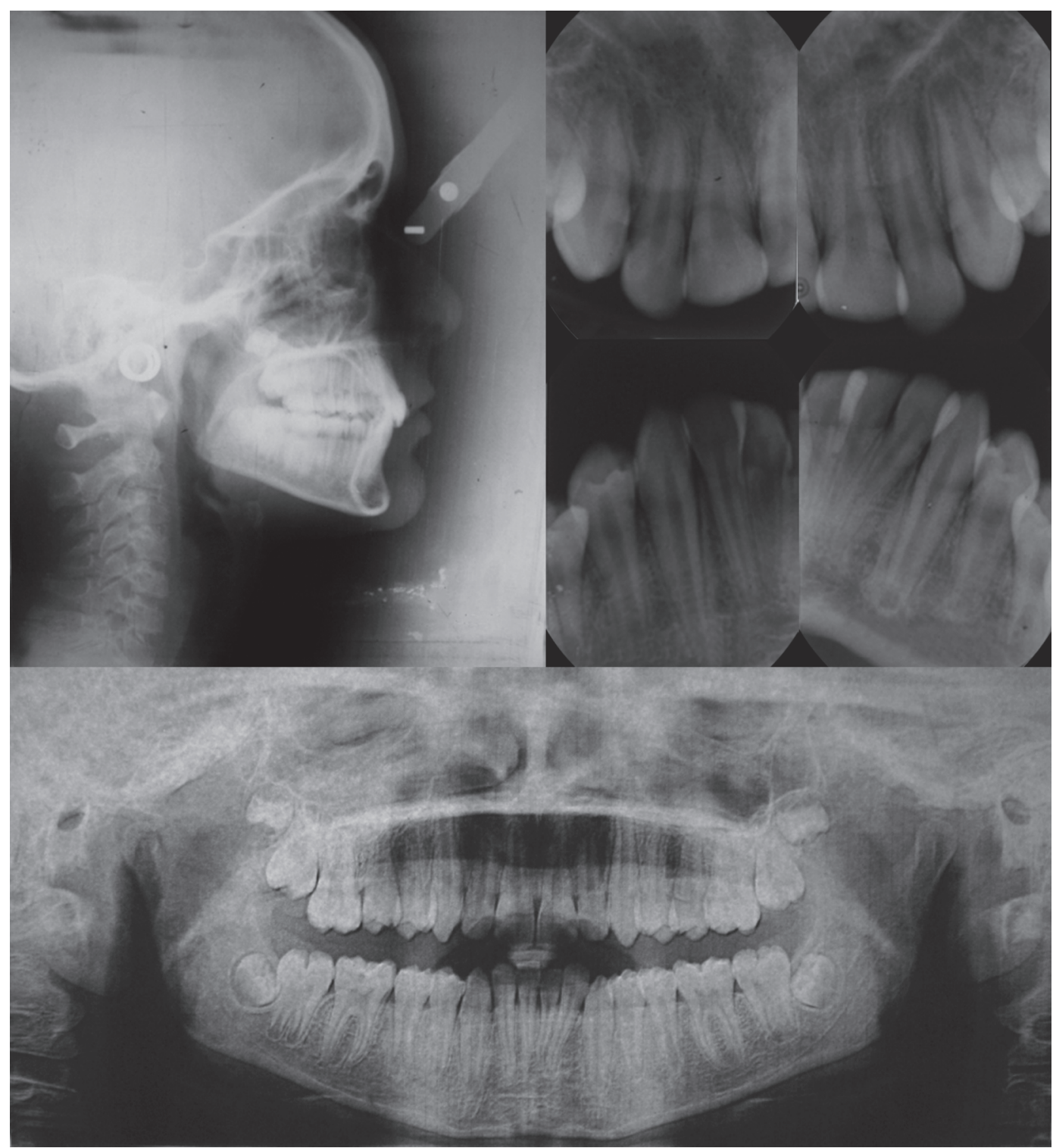

Fig. 2: Pretreatment extraoral and intraoral radiographs

treatment progressed, upper $0.019 \times 0.025$ SS wire was given and $0.016 \mathrm{NiTi}$ in the lower arch. After a few months, a curve of Spee was incorporated in the upper arch with $0.019 \times 0.025$ SS wire, and in the lower arch, reverse curve of Spee was given with 0.019 $\times 0.025 \mathrm{SS}$ wire. For the final part of the repositioning, upper and lower arches were given $0.018 \mathrm{NiTi}$ wires. For finishing and detailing of the treatment, 0.016 AJ Wilcock wires were placed along with triangular settling green elastics in the posterior teeth. After debonding, lingual-bonded retainers were placed from the two lateral incisors on each side in the upper arch and from the canines on either side in the lower arch (Fig. 4).

\section{Discussion}

Class II division 2 malocclusions represent a specific irregularity in bite, which is characterized by a specific ratio of teeth and jaw bases. A distinct skeletal profile of the patients is a protruded nose, subnasal, and mental region, along with the following specific dentoskeletal features: ${ }^{4}$

- Orthognathic maxilla and mild retrognathic mandible

- Stark horizontal growth pattern along with the frontal rotation of the mandibular base

- Skeletal deep bite

- Retroclination and supraposition of the upper incisors, and

- Small teeth, pronounced growth of mandibular base, and a strong chin.

Soft-tissue profile in class II division 2 is a profile of "sharp" facial contours with concave lower third of the face with a protruding nose and tip of the chin, thin vermillion, and retruded lips. The protrusion type utility arch is useful in the proclination of upper and lower incisors. ${ }^{5}$ It is commonly employed for flaring and intrusion of the upper incisors in Angle's class II division 2 type 
Table 1: Pretreatment and posttreatment cephalometric values

\begin{tabular}{llll}
\hline Cephalometric evaluation variable & Normal & Pretreatment & Posttreatment \\
\hline SNA & $82^{\circ}$ & $75^{\circ}$ & $74^{\circ}$ \\
SNB & $80^{\circ}$ & $73^{\circ}$ & $73^{\circ}$ \\
ANB & $2^{\circ}$ & $2^{\circ}$ & $1^{\circ}$ \\
Wits & $\mathrm{F} 0 \mathrm{~mm}$ & $2 \mathrm{~mm}$ & $2 \mathrm{~mm}$ \\
& $\mathrm{M}+1 \mathrm{~mm}$ & & $10 \mathrm{~mm} / 39^{\circ}$ \\
U1 to NA (mm/deg) & $4 \mathrm{~mm} / 22^{\circ}$ & $3 \mathrm{~mm} / 16^{\circ}$ & $8 \mathrm{~mm} / 32^{\circ}$ \\
L1 to NB (mm/deg) & $4 \mathrm{~mm} / 25^{\circ}$ & $4 \mathrm{~mm} / 20^{\circ}$ & $67^{\circ}$ \\
U1 to SN & $102^{\circ}$ & $89^{\circ}$ & $101^{\circ}$ \\
L1 to MP & $90 \pm 3^{\circ}$ & $91^{\circ}$ & $108^{\circ}$ \\
Interincisal angle & $135^{\circ}$ & $141^{\circ}$ & $5 \mathrm{~mm}$ \\
L1 to A-pog line & $1-2 \mathrm{~mm}$ & $-2 \mathrm{~mm}$ & $-8 \mathrm{~mm}$ \\
N perpendicular to point A & $0 \pm 1 \mathrm{~mm}$ & $-2 \mathrm{~mm}$ & $-11 \mathrm{~mm}$ \\
N perpendicular to Pog & $0-4 \mathrm{~mm}$ & $-6 \mathrm{~mm}$ & $30^{\circ}$ \\
Maxillary-mandibular planes angle & $25^{\circ}$ & $26^{\circ}$ & $39^{\circ}$ \\
SN plane-mandibular plane & $32^{\circ}$ & $39^{\circ}$ & $61.56 \%$ \\
Jarabak ratio & $62-65 \%$ & $60 \%$ & $84 \mathrm{~mm}$ \\
Maxillary length (McNamara) & & $87 \mathrm{~mm}$ & $112 \mathrm{~mm}$ \\
Mandibular length - effective (McNamara) & & $108 \mathrm{~mm}$ & $-5 \mathrm{~mm}(\mathrm{UL})$ \\
Lower lip to Ricketts E plane & $-2 \mathrm{~mm}$ & $-4 \mathrm{~mm}(\mathrm{UL})$ & $-2 \mathrm{~mm}(\mathrm{LL})$ \\
Nasolabial angle & $102 \pm 8^{\circ}$ & $-2 \mathrm{~mm}(\mathrm{LL})$ & $116^{\circ}$ \\
\hline
\end{tabular}
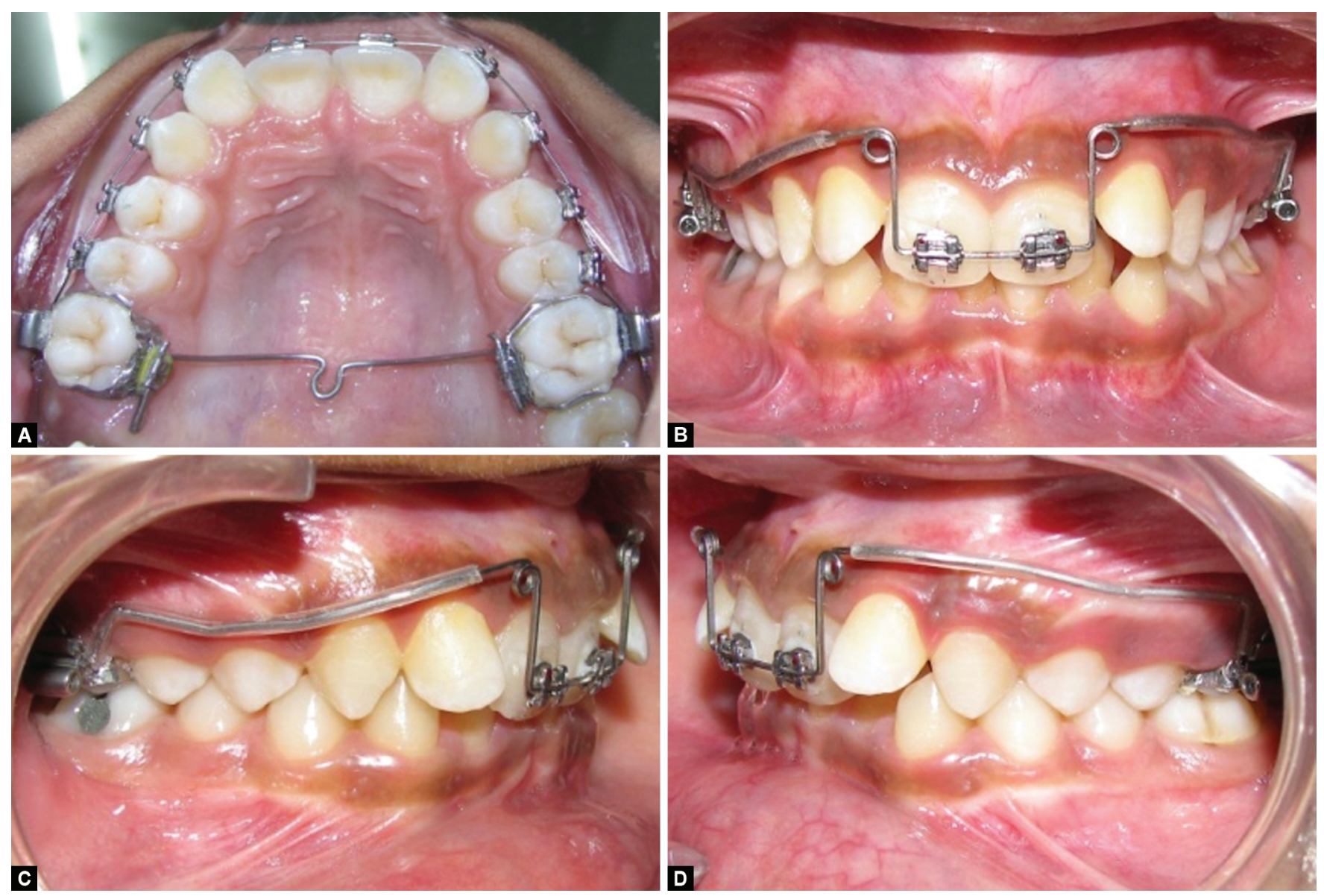

Figs 3A to D: Protraction and retraction utility arch 

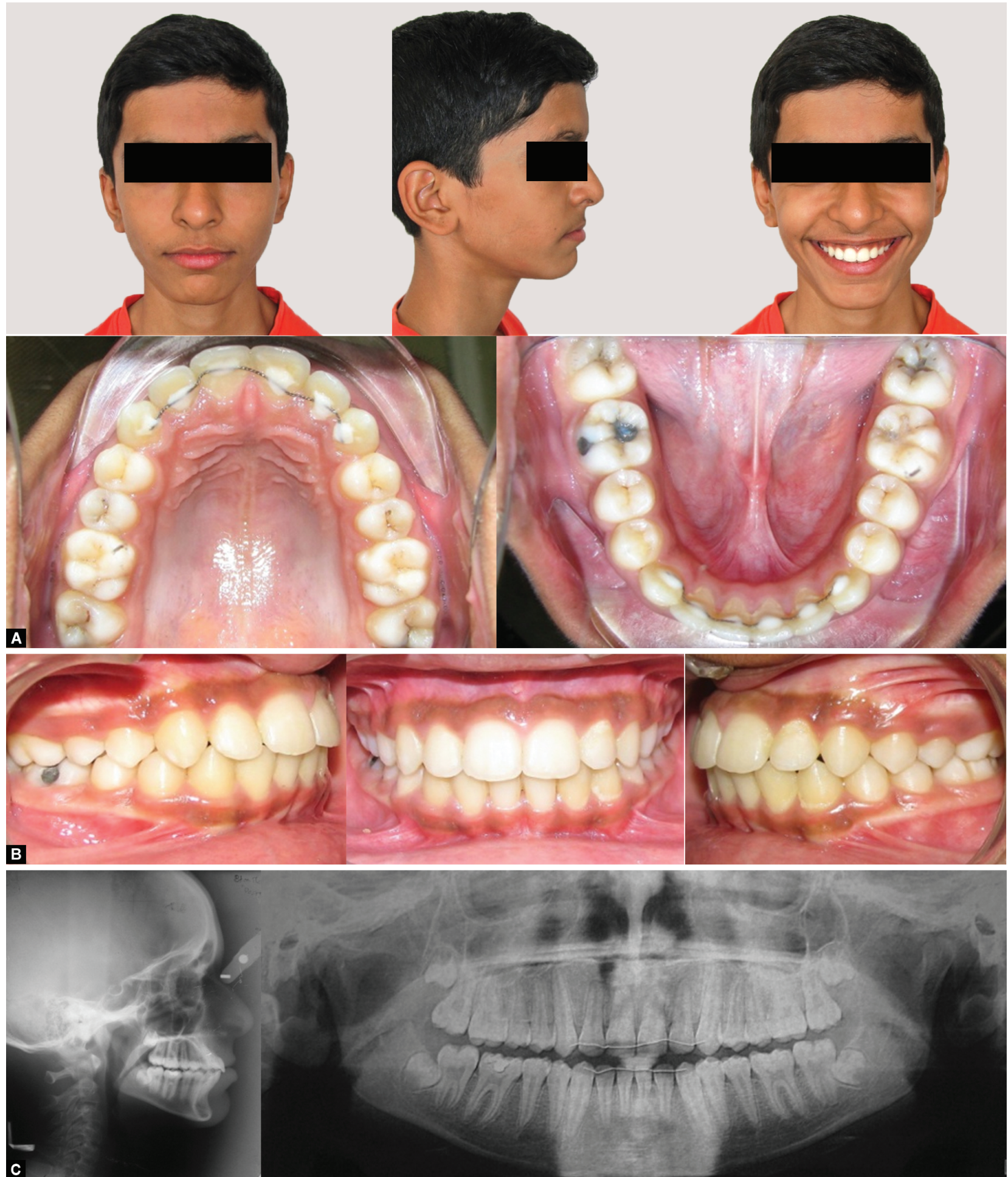

Figs 4A to C: Posttreatment extraoral and intraoral photographs and radiographs

malocclusions. Hence, for this patient, it was planned to give the protraction utility arch for proclining the upper central incisors for their alignment in accordance to the rest of the dentition in maxillary arch.

\section{References}

1. AtikE, Kocadereli I. Treatment of class II division 2 malocclusion using the Forsus fatigue resistance device and 5 -year follow-up. Case Rep Dent 2016;2016:3168312. DOI: 10.1155/2016/3168312.
2. Perović T. Class II/2 malocclusions and the face profile harmony. Med Sci Monit 2017;23:5589-5598. DOI: 10.12659/MSM.905453.

3. Silvia R, Valeria S, Andrés G, et al. Adolescent patient; treatment; maxillary molars; space;crowding. J Orthod Endod 2017;3(4):13. DOI: 10.21767/2469-2980.100047.

4. Strang R. Class II division 2 malocclusion. Angle Orthodontist 1958;28(4):210-214.

5. Rakesh A, Reddy V, Reddy D. Utility arches in orthodontics case reports. Ann Essences Dent 2011;3(1):60-64. DOI: 10.5368/ aedj.2011.3.1.2.5. 